\title{
Students' perspectives about the medical humanities curriculum at the Catholic University of Korea
}

\author{
Wha Sun Kang1, Seon-Hee Yim², Ilene Harris ${ }^{3}$, Hyunjoo $\mathrm{Na}^{4}$, Pyeong Man Kim ${ }^{5}$ \\ ${ }^{1}$ Department of Medical Lifescience, College of Medicine, The Catholic University of Korea, Republic of Korea \\ ${ }^{2}$ Department of Medical Education, College of Medicine, The Catholic University of Korea, Republic of Korea \\ ${ }^{3}$ Department of Medical Education, College of Medicine, University of Illinois at Chicago, USA \\ ${ }^{4}$ Department of Health Systems Science, College of Nursing, University of Illinois at Chicago, USA \\ ${ }^{5}$ Department of Humanities and Social Medicine, College of Medicine, The Catholic University of Korea, Republic of Korea
}

Correspondence: Wha Sun Kang, Department of Medical Lifescience, College of Medicine, The Catholic University of Korea, 222, Banpo-daero, Seocho-gu, Seoul 137-701, Republic of Korea. E-mail: wskang@catholic.ac.kr

\begin{abstract}
Objectives: This paper presents the results of a qualitative study aimed at elucidating how well the goals of the OMNIBUS curriculum implemented in Korea as a medical humanities curriculum were achieved, from the student perspective.

Methods: We conducted a qualitative study to elicit perspectives of students who participated in all 12 weeks of the OMNIBUS curriculum. Eighteen fourth-year medical students participated in two focus group interviews. Openended questions were prepared to guide the interviews. The interviews were audio-taped and transcribed. All data from the interviews were analyzed, using an inductive approach to identify themes.
\end{abstract}

Results: The main themes were "characteristics of a good doctor", "various careers in medicine", and "the need for changes in assessment methods". Seven subthemes that emerged were specifically related to "characteristics of a good doctor", including "variety of perspectives on the human condition", "feel empathy with patients from diverse backgrounds", "communicate effectively with patients", "clarify values", "roles as a leader in society", "give back to the community", and "satisfaction of being physicians and importance of physician self-care".

Conclusion: The themes identified in this study demonstrated that the OMNIBUS curriculum achieved its goals, from the student perspective. In the interviews, students also identified other strengths and areas for improvement of the curriculum.

Keywords: Qualitative study, OMNIBUS curriculum, medical humanities education, characteristics of a good doctor, Korea

\section{Introduction}

Medical education aims at improving patient care. Specifically, the fundamental requirement of improving patient care is to produce "good doctors". Perceptions of characteristics of "good doctors" periodically change, in part related to social, cultural, and economic contexts. ${ }^{1}$ Currently, "good doctors" are perceived as able to apply medical knowledge and skills, with a holistic understanding of the patient, modifying their approaches in relation to the individual patient. Macnaughton defined a "good doctor" as demonstrating sensitivity in dealing with patients, based on knowledge of herself and her own values, and insight into the problems and contexts of patients' lives. ${ }^{2}$ She also said that doctors need to be able to assimilate scientific knowledge of disease and treatments with an understanding of the individual patient, and they need to exercise good clinical judgment as to what might be of benefit to this patient with this particular problem at this point in his life.

It has been argued that medicine has been dehumanized, because of the biomedical model influencing medicine and medical education since the mid- $19^{\text {th }}$ century and the application of biotechnologies unaccompanied by philosophical reflection. As a consequence, there are ethical problems in the behavior of medical professionals. ${ }^{3,4}$ As one potential solution to these problems, it has been suggested 
that the humanities and social sciences need to be integrated into medical education. ${ }^{5,6}$

Some medical schools have implemented medical humanities curricula, but most schools have not systematically evaluated their programs or identified student outcomes. ${ }^{7}$ Wachtler et al. ${ }^{8}$ conducted a qualitative study of their humanities curriculum at Lund University, concluding that, despite the challenges of creating a cross-disciplinary curriculum, they had created an interdisciplinary learning environment.

For decades, there has been a trend towards establishing medical humanities as a component of medical education in Korea. Humanities content, primarily ethical issues, was introduced in the early 1980s in the medical colleges of The Catholic University of Korea (CUK) and Yonsei University. Currently, all the medical schools in Korea have implemented humanities curricula in various ways. ${ }^{4,9,10}$ The Korean Association of Medical College and Graduate Medical School stress the importance of humanities curricula, including medical ethics, and have announced plans to evaluate these curricula and the work experience and community service programs linked with them. ${ }^{11}$

The medical college of CUK established the Department of Humanities and Social Sciences in 2006. In 2007, it began to develop a medical humanities curriculum, referred to as the OMNIBUS curriculum, which was implemented in 2009 and modified to the present time, through a continuous process of review. OMNIBUS, the name of the humanities curriculum, was taken from the Latin expression "to all men" in First Corinthians of the Bible, and was chosen to refer to a holistic understanding of the human. We focused on traditional humanities content, such what as art, music, and literature mean to a suffering human, and approached the curriculum development based on the inherent dignity of the human and the moral values of Catholic teaching. The goals of the OMNIBUS curriculum are to educate medical students to be medical professionals, who embody a Catholic identity, with an understanding of humane and holistic medicine, and medical professionalism. The current focus on medical professionalism in the curriculum often begins with how best to instill or encourage the following six elements of professionalism: altruism, accountability, excellence, duty, honor and integrity, and respect for others. ${ }^{12}$ The humanities offer great potential for enhancing professional and humanistic development in medical education. ${ }^{13,14}$ We take an inter-disciplinary approach, with perspectives from various humanities and social science disciplines, such as philosophy, history, sociology, and economics, so that students can foster professionalism as a vital, continuous process to be compassionate toward others, communicative with others, mindful to understand humans holistically, and socially responsible through a curriculum that draws from various disciplines and methods. The faith-based curriculum, while do not demanding faith, provides opportunities for pervasive reflection to help and lead students to examine the values and goals of medical care. This faith-based, medical humanities curriculum is unique in Korea. The medical college's significant resources, including 50 faculty members who have participated in developing and implementing the OMNIBUS curriculum, are also regarded as unique. In 2013, students who participated in all four years of the curriculum graduated from the medical college of CUK. Therefore, this is an appropriate time to evaluate the outcomes and processes of the OMNIBUS curriculum.

The purpose of this paper is to describe the goals, objectives, and content of our OMNIBUS curriculum and present the results of a qualitative study of focus group interviews to elucidate how well the OMNIBUS curriculum goals were achieved from the student perspective.

\section{Methods}

\section{Program description}

The OMNIBUS curriculum is a longitudinal program that consists of 12 segments during 12 weeks of a 4 -year medical education, and it is intercalated in the medical curriculum. The content and items of each segment of the OMNIBUS curriculum were developed to correspond with block lectures of the integrated medical curriculum. The purpose of the OMNIBUS curriculum is to restore the "art" of medicine in order to produce physicians who are "Healers" as expressed in "The Charter for Health Care Workers". ${ }^{15}$ The segments in Years 1 and 2 focus on the understanding of holistic medicine. During these pre-clinical years, students are encouraged to reflect on the human condition, holistic medicine, and the roles of doctors. The segments in Years 3 and 4 focus on knowledge, skills, and attitude from the perspectives of medical professionalism. During these clinical years, students develop an ethical and compassionate attitude as they exercise their professional responsibilities towards patients and communities. Students also learn how to be empathetic with the situation of each patient through participating in team activities of the community outreach program and working with the poor and sick for four days. The course segments and goals are shown in Table 1.

\section{Data collection}

The focus group interview (FGI) was chosen as the method to obtain data for this evaluation study, because focus groups can be effective for group members to stimulate others to generate ideas. FGIs are also an efficient way to learn about participants' perspectives on their experiences and outcomes. ${ }^{16}$

FGIs were conducted with fourth-year medical students who participated in all 12 weeks of the OMNIBUS curriculum and were to graduate from the medical college of CUK in 2013. Two separate FGIs (8 and 10 students, respectively; 11 male and 7 female students in total) were conducted in November 2012. The interviews were facilitated by one of 
the authors and observed by one assistant. Before they began, written consent was obtained from all the participants for ethical considerations and Institutional Review Board (IRB) approval. Participation was voluntary. Explanations of audio-taping were provided, and anonymity and confidentiality were stressed. The assistant's field notes were used to capture observations of individuals during the FGIs. In order to ensure consistency across groups, the openended trigger questions in the Appendix were used to guide the FGIs and were provided to participants, to write down their perspectives, 30 minutes before the interview. These written data were also used in the analysis to identify themes.

Table 1. Examples of medical humanities segments in the OMNIBUS curriculum at the College of Medicine, The Catholic University of Korea

\begin{tabular}{|c|c|c|}
\hline Titles & & Goals \\
\hline \multirow[t]{2}{*}{ Year1 } & - Foundation & $\begin{array}{l}\text { Introduction of the OMNIBUS } \\
\text { curriculum }\end{array}$ \\
\hline & $\begin{array}{l}\text { - Medicine and } \\
\text { Humanities I }\end{array}$ & $\begin{array}{l}\text { Holistic understanding of the human } \\
\text { and medicine }\end{array}$ \\
\hline \multirow[t]{4}{*}{ Year2 } & $\begin{array}{l}\text { - Community Outreach } \\
\text { Program }\end{array}$ & $\begin{array}{l}\text { Holistic understanding and practice to } \\
\text { address human disease, suffering, } \\
\text { and treatment }\end{array}$ \\
\hline & $\begin{array}{l}\text { - Medicine and } \\
\text { Humanities II }\end{array}$ & $\begin{array}{l}\text { Holistic understanding of the human } \\
\text { and medicine }\end{array}$ \\
\hline & - Leadership Training & $\begin{array}{l}\text { Self- management and development } \\
\text { of self-efficacy based on self- } \\
\text { understanding }\end{array}$ \\
\hline & $\begin{array}{l}\text { - Medicine and } \\
\text { Humanities III }\end{array}$ & $\begin{array}{l}\text { Holistic understanding of the human } \\
\text { and medicine }\end{array}$ \\
\hline \multirow[t]{4}{*}{ Year3 } & $\begin{array}{l}\text { - Medical Professional- } \\
\text { ism }\end{array}$ & $\begin{array}{l}\text { Cultivate competencies and attitudes } \\
\text { of physicians }\end{array}$ \\
\hline & - Medical Ethics & $\begin{array}{l}\text { Develop high standards of ethics in } \\
\text { research and medicine }\end{array}$ \\
\hline & $\begin{array}{l}\text { - Medicine and Society } \\
\text { I }\end{array}$ & $\begin{array}{l}\text { Develop leadership skills, with social } \\
\text { responsibility }\end{array}$ \\
\hline & $\begin{array}{l}\text { - Medicine and Society } \\
\text { II }\end{array}$ & $\begin{array}{l}\text { Develop leadership skills, with social } \\
\text { responsibility }\end{array}$ \\
\hline \multirow[t]{2}{*}{ Year4 } & $\begin{array}{l}\text { - Medical Law and } \\
\text { Research Ethics }\end{array}$ & $\begin{array}{l}\text { Develop skills to make ethical } \\
\text { judgments }\end{array}$ \\
\hline & $\begin{array}{l}\text { - Planning for the } \\
\text { Future: Career and } \\
\text { Research Interests }\end{array}$ & $\begin{array}{l}\text { Teamwork for enrichment and career } \\
\text { development }\end{array}$ \\
\hline
\end{tabular}

\section{Data analysis}

Inductive analysis was used to identify themes in the FGIs. Audio-taped oral responses in the FGIs were transcribed. Observational notes, written data, and transcribed text were analyzed. As the first step of analysis, two independent researchers (WK \& HN) read the transcribed text to familiarize themselves with the content, without any intention of categorization. Subsequently, two researchers identified themes in the FGIs and categorized them independently. Each researcher's results were checked for similarity of meaning, and themes were added, subtracted, or modified to reach an agreement. All authors then reviewed and discussed the themes in relation to the data to reach consensus. ${ }^{17-19}$ Excerpts from the FGIs were selected to illustrate each theme.

\section{Ethics}

Ethics approval was sought and obtained from the IRB of Songeui Medical Campus, The Catholic University of Korea.

\section{Results}

Two groups (18 $4^{\text {th }}$-year medical students) participated in focus group interviews. Overall, students thought the OMNIBUS curriculum was valuable in their medical education, for learning humanities and social sciences perspectives not available in other parts of the curriculum. As one student commented,

"Medical students generally focus on medicine and show concerns about their careers as physicians. So I think that this curriculum addressed the goals just by providing opportunities for students to think about the necessities of medical humanities in their life." (Female participant, no. 2)

Consistent with the trigger questions, three themes were identified in comments made by a majority of students. These themes related to the characteristics of a good doctor, various careers in medicine, and the need for changes in assessment methods.

\section{Characteristics of a good doctor}

Students commented that the OMNIBUS curriculum helped them to identify and develop the characteristics of a good doctor. As one student commented,

\footnotetext{
"This curriculum showed what "good doctors" were. Now I can define the concept of "a good doctor". This curriculum showed the characteristics of "a good doctor" over several weeks'." (Male participant, no. 9)
}

In the FGIs, many students commented about many attributes of a good doctor and aspects of the OMNIBUS curriculum that helped them to develop these attributes. For example, the Omnibus curriculum provided for experiential learning, observing videotaped examples, meeting with role models, and discussing specific issues with peers, all activities in which they have chances to see or hear, directly or indirectly, examples of good doctors, and to think about the attributes of good doctors. They were impressed that doctors who they viewed as role models did valuable work, practicing their profession with love and service throughout their lives. Seven sub themes were identified related to the theme, 'Characteristics of a good doctor', as described below.

\section{Variety of perspectives on the human condition}

Students commented that the OMNIBUS curriculum presented a variety of perspectives on the human condition, such as the spiritual, the sociological, and the medical perspectives, which they were committed to understanding, valuing and addressing, as contrasted with focusing on the 
Kang et al. - Students' perspectives about the medical humanities curriculum

disease or treatment perspectives. Examples of comments included:

"I learned the spiritual perspective of human being in 'Spiritual Theology' class that I had never heard or thought about this before the class." (Male participant, no. 6)

"Doctors do not cure the disease but understand and cure the human." (Female participant, no. 7)

\section{Feel empathy with patients from diverse backgrounds} A number of students commented that physicians should deal competently and compassionately with patients from all backgrounds, demonstrating empathy. In this connection, they commented that they had the opportunity to feel and express empathy when they met and interviewed real patients in their courses and stayed with the sick and poor in community outreach program. One student commented:

"When I meet the patients as a physician in the future, I need to be empathetic to understand the patients who have different backgrounds and values, and live in different environments different from me." (Female participant, no. 1)

\section{Communicate effectively with patients}

Students commented that developing communication and interpersonal skills was essential to being good doctors. They said they learned to communicate with others through putting themselves in others' place in debates and role play. They needed to put themselves in patients' positions before making a decision as physicians. As one student commented,

"It was effective for developing communication skills to think about specific issues from opposite angles." (Male participant, no. 11)

Students also commented that expressing their perspectives is an additional competency related to communication. For example, a student commented:

"I felt uncomfortable when I had to write my opinion or think about my thought for a debate class, but I realized that those assignments were really useful to me to collect my thoughts and set up my own opinion." (Male participant, no. 3)

\section{Clarify values}

Students said that the OMNIBUS curriculum helped them to clarify their values. Specifically, the OMNIBUS curriculum provided the time for students to think about various ethical and moral issues related to health professions, which could help them to make better decisions in various clinical situations. For example, a student commented:

"Helpful because physicians will meet many cases in which they need to judge the values." (Female participant, no. 4)

\section{Roles as a leader in society}

Students commented that the OMNIBUS curriculum helped them understand the status and possible roles of physicians in society and also their role as leaders in addressing health system problems. Some comments included:

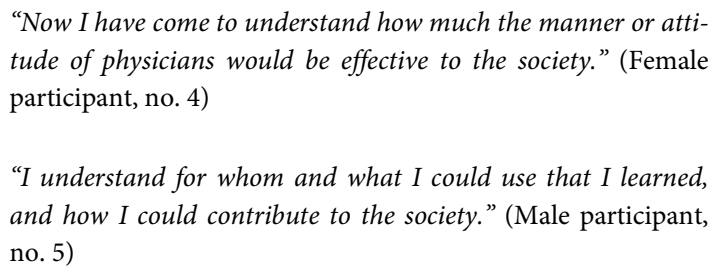

"I understand for whom and what I could use that I learned, and how I could contribute to the society." (Male participant, no. 5)

\section{Give back to the community}

Students commented that the OMNIBUS curriculum helped them to be doctors who gave back to their community. Most students acknowledged that their experiences of staying with the poor and sick for four days in 'Kot-Dong$\mathrm{Ne}$ ', for their outreach community service, may have considerably impacted them to understand the true meaning of community service and their vocation. They especially valued this program as they could have first-hand experience with community service, to learn to help others and contribute to public welfare. Examples of comments included:

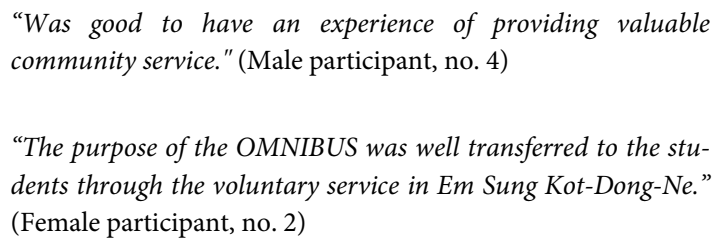

"The purpose of the OMNIBUS was well transferred to the students through the voluntary service in Em Sung Kot-Dong-Ne." (Female participant, no. 2)

The satisfaction of being physicians and importance of physician self-care

Students talked about the satisfaction of being physicians as one requirement for being good doctors. Through the OMNIBUS curriculum, they realized the necessity of rest and leisure for physicians, in part to overcome stress, with effective self-management between work and leisure generating a significant synergy. As one student commented,

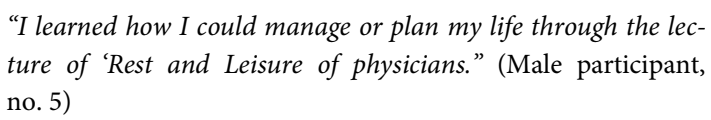

Sub themes identified related to 'Characteristics of a good doctor' showed that students have learned and were motivated to be good doctors through the OMNIBUS curriculum. Students described the attributes of good doctors as regards their calling as physicians in the future.

\section{Various careers in medicine}

Students commented that the OMNIBUS curriculum helped them to gain better and broader insights about 
various careers as physicians by meeting guest instructors with different specialties. Students were also motivated to consider various careers in medicine, by peer discussion, when they presented their decision about their vocation in the 'Capstone' course. The subject of the Capstone course was 'planning for the future: career and research interests' (Table 1). In this course, all students worked on a groupspecific project and presented their projects to the other students. Because it was the final course of the OMNIBUS curriculum, students regarded this course as the time for their summary and synthesis of the OMNIBUS. Some comments included:

"I could give shape to my plan about how I was going to live in the future as a physician". (Male participant, no. 11)

"Capstone course was really helpful to me to decide my career." (Male participant, no. 7)

Because most students didn't think about other careers except as physicians, they were motivated and enthusiastic to think about their possible vocations.

\section{The need for changes in assessment methods}

Students commented that the current assessment methods were not appropriate for the OMNIBUS curriculum. Some courses included assessment methods such as writing, participation in a debate, or group work, however other courses used multiple choice or short answer questions for assessment. Students thought that they should not be assessed with written tests, such as multiple choice questions (MCQ) or short answer questions at the end of courses, for grading. They thought that the assessment methods for the OMNIBUS curriculum should not assess how much students know, but rather assess how much they understand and apply. Some comments included:

\footnotetext{
"The MCQ was the worst method for the OMNIBUS curriculum." (Male participant, no. 4)

"Can't understand to assess the learning outcomes of the OMNIBUS by MCQ or short answer questions." (Male participant, no. 8)
}

Students suggested various assessment methods, such as submitting reports about what they felt or understood and group discussion about specific issues related to the subject of the course. Some students commented about the value of using several assessment methods for each course, while one student recommended selecting one appropriate assessment method, consistent with the objectives of each course.

\section{Discussion}

This is the first qualitative study of students' perspectives on humanities curricula in medical education in Korea. Although we have quantitative data indicating high satisfaction ratings ( $4.3 / 5$ when 5 is most positive; data not published), we need to understand the rationales for students' satisfaction with the humanities curriculum, in order to evaluate and improve the curriculum. Curriculum evaluation is one of the best ways to drive the development and evolution of the curriculum. Curriculum evaluation can contribute toward program improvement and decisions about whether to continue programs, to initiate new programs, or to change the funding or structure of a program. ${ }^{20}$ Medical students are viewed as a reliable and valid source of information in curriculum evaluation because they observe teaching and participate in classes. ${ }^{21}$

We conducted FGIs to obtain qualitative feedback from students about the OMNIBUS curriculum, which was implemented over a span of four years. FGIs have been shown to be an appropriate method for course evaluation, for understanding what students learn in relation to the curriculum, what values they develop in relation to the curriculum, and what specific problems they think should be addressed to improve the curriculum. ${ }^{22}$ Data from these interviews helped us to understand student perspectives on all elements of the curriculum, including perspectives on the extent to which goals and objectives have been achieved. In addition, data from the FGIs will guide decision-making for future course improvement. FGIs are also a good way to elicit variations in perspectives among individuals and groups about the same issues. These different views were helpful to stimulate us to consider and develop better ways to motivate students to be more responsive to the curriculum.

The term "medical humanities" was first used in 1976 by A.R. Moore, an Australian doctor. ${ }^{23} \mathrm{He}$ used excerpts from literatures to review the notion of "doctorship" from different perspectives, such as philosophical, cultural, and individual perspectives. The Academic Association for Medical Humanities of England defined the medical humanities as the study that searches for humane aspects of medicine, using an interdisciplinary approach. ${ }^{24}$ Humanities have been described as a means to achieve the goal of fostering the generic "good" (empathic, holistically oriented) doctor. ${ }^{25}$ Being a good doctor, from a humanities perspective, includes not only having knowledge of scientific medicine, but also being a "humane doctor."

The major goals of the OMNIBUS curriculum are to educate medical professionals who are compassionate and demonstrate a holistic understanding of the human condition. It is noteworthy that the medical college of CUK, as a Catholic medical school, has at least a "hidden" curriculum of students developing values consistent with a Catholic identity, such as an open attitude to professional vocation, spiritual and personal maturity, a high level of empathy, high ethical standards, servant leadership, and a high sensitivity to social justice. While some students reported about their experiences of Catholicism in the curriculum, other students felt that they did not have any experiences related to Catholicism. These different perspectives indicate 
that Catholicism is a "hidden" component of the OMNIBUS curriculum. Hafferty and Franks argued that most of the critical determinants of physicians' identity operate not within the formal curriculum but in a more subtle, less officially recognized "hidden curriculum." ${ }^{26}$ The hidden curriculum refers to the "processes, pressures and constraints which fall outside... the formal curriculum, and which are often unarticulated or unexplored." ${ }^{27}$ Hidden aspects of the curriculum have been viewed as especially important for professional education, and specifically for medical education. Six learning outcomes of the hidden curriculum have been identified: loss of idealism, adoption of a "ritualized" professional identity, emotional neutralization, change of ethical identity, acceptance of hierarchy, and learning of less formal aspects of "good doctoring." ${ }^{28}$ It is likely that Catholicism, as a hidden part of the curriculum, helped students to explore their ethical and professional identity, as well as to learn various perspectives of the "good doctor." Students were in agreement that Catholicism did not appear to be emphasized regularly in courses, but they were able to identify a "hidden curriculum" of Catholic values.

Overall, including medical humanities as part of health care professionals' basic training was regarded by students as pivotal in helping to shape their future, both as compassionate practitioners and as reflective human beings. ${ }^{29}$ This study aims at examining perspectives of changes in student behavior as a first step in the evaluation of the OMNIBUS curriculum. The next study will examine the fundamental question of whether significant resources allocated to the medical humanities curriculum in South Korea can lead to improved student outcomes.

Experiential learning is one of the most powerful teaching and learning methods. ${ }^{30}$ Reflection and reflective practice are regarded as important parts of the experiential learning processes and have been shown as essential to the development of medical professionalism related to humanism, building individual reflection, fostering empathy, increasing understanding and appreciation for the community and the society, building community, and enhancing cultural competence. ${ }^{31-34}$ Many kinds of reflection exercises have been reported to stimulate and motivate reflection on specific issues. ${ }^{35}$ Our data indicated that students were motivated to reflect on their development as physicians through experiential leaning. They commented about, and valued, all the methods used in the OMNIBUS curriculum, such as role-play, writing, group discussion, debate class, and community service. They were encouraged to take opportunities to reflect on different situations, which led them to understand the spirit, attitude, and required competencies of good doctors. They were also motivated to become "good" doctors through learning experiences, such as watching videos of those worthy of emulation. Students spoke of "meeting" and "being acquainted" with role models. This study illustrates how a humanities curriculum, with a multifaceted instructional methodology, led to achievement of the curriculum goals.

In medical education, the importance of outcome-based education has been increasingly emphasized. ${ }^{36,37}$ Educators agree that assessment drives learning. Assessment can motivate and focus both learners and teachers to address learning gaps they might overlook. ${ }^{38}$ The main humanities curriculum learning outcome is stated as being "to recognize and appreciate both the scientific and the experiential 'mystery' of embodied human nature and to bring this to bear on the students' conception of their own clinical practice." ${ }^{39}$ Yet specifically for medical humanities education, it is difficult to assess the outcome of students just after they have taken courses. Several assessment methods were implemented at the end of each course in the OMNIBUS curriculum, as existing regulations require assessment. Most students prefer assessment activities such as creative writing or group discussions to multiple-choice or short-answer questions. Various assessment methods are used to measure student outcomes in medical education. ${ }^{2,40}$ Evans argued that many important learning outcomes are difficult to assess, except retrospectively at the end of a clinical career. ${ }^{39}$ Nevertheless, it should be our next step to increase the validity and effectiveness of current assessment methods and develop new assessment methods consistent with the goals of the humanities curriculum.

The present study has several limitations. The 18 students who participated in the FGIs may not be representative of all students, but the number of students included was within the appropriate range as described in other research. ${ }^{41,42}$ In addition, the choice to have the FGIs facilitated by CMC faculty could risk discouraging students from voicing their opinions or criticizing the curriculum. To reduce this possibility, the FGI facilitator was a faculty who did not participate in curriculum planning and teach courses for those years.

Finally, through this study, we support the view that long-term investments in humanities curricula in medical education increase the potential to develop students into humane doctors.

\section{Conclusion}

This qualitative study demonstrated that the OMNIBUS curriculum achieved its aims. Qualitative student feedback on the curriculum helped to identify the strengths and weakness of the OMNIBUS curriculum and underlined certain key issues to be improved, specifically the assessment methods.

\section{Acknowledgement}

The authors wish to acknowledge the financial support of the Catholic Medical Center Research Foundation made in the program year of 2010. We also thank all those who participated in the research. 


\section{Conflict of Interest}

The authors declare that they have no conflict of interest.

\section{References}

1. Lee YM, Ahn DS. A preliminary study for exploring the attributes of being a "Good Doctor". Korean Journal of Medical Education. 2007;19(4):313-23.

2. Macnaughton J. The humanities in medical education: context, outcomes and structures. Medical Humanities. 2000;26(1):23-30.

3. Duffin J. History of medicine: a scandalously short introduction. Toronto, Buffalo: University of Toronto Press; 1999.

4. Meng KH. Teaching medical humanities in Korean medical schools: tasks and prospect. Korean Journal of Medical Education. 2007;19(1):5-11.

5. Glick SM. Sounding board. Humanistic medicine in a modern age. The New England Journal of Medicine. 1981;304(17):1036-8.

6. Evans H, Macnaughton J. Should medical humanities be a multidisciplinary or an interdisciplinary study? Medical Humanities. 2004;30(1):1-4.

7. Whittaker M, Dittrich L. Special theme: humanities education. Academic Medicine. 2003;78:953-1075.

8. Wachtler C, Lundin S, Troein M. Humanities for medical students? A qualitative study of a medical humanities curriculum in a medical school program. BMC Medical Education. 2006;6(6):16.

9. Chen W, Yang E. Medical humanities and the future of medical education. Seoul: Yonsei University Publishing Office; 2003.

10. An JH, Kwon I, Lee SN, Han JJ, Jeong JE. Study on the medical humanities and social sciences curriculum in Korean medical school: current teaching status and learning subjects. Korean Journal of Medical Education. 2008;20(2):133-44.

11. Medical humanities and social sciences curriculum development. Seoul: Korean Association of Medical Colleges; 2007.

12. Wear D, Castellani B. The development of professionalism: curriculum matters. Academic Medicine. 2000;75(6):602-11.

13. Meakin R. Teaching medical students professionalism: what role for the medical humanities? Medical Humanities. 2007;33(2):105

14. Shapiro J, Coulehan J, Wear D, Montello M. Medical humanities and their discontents: definitions, critiques, and implications. Academic Medicine. 2009;84(2):192-8

15. The Pontifical Council for Pastoral Assistance to Health Care Workers. The charter for health care workers. Vatican City, 1995 [cited 15 October 2013]; Available from: http://www.vatican.va/roman_curia/pontifical _councils/hlthwork/.

16. Stewart DW, Shamdasani PN. Focus groups: theory and practice. Newbury Park, Calif.: Sage; 1999.

17. Krueger RA. Focus groups: a practical guide for applied research $2^{\text {nd }} \mathrm{ed}$. Thousand Oaks, Calif: Sage Publications; 1994.

18. Rabiee F. Focus-group interview and data analysis. The Proceedings of the Nutrition Society. 2004;63(4):655-60.

19. Tempski P, Bellodi PL, Paro HB, Enns SC, Martins MA, Schraiber LB. What do medical students think about their quality of life? A qualitative study. BMC Medical Education. 2012;12:106.

20. Fitzpatrick JL, Sanders JR, Worthen BR. Program evaluation: alternative approaches and practical guidelines. Boston, Mass: Pearson; 2012.

21. Ranasinghe $\mathrm{P}$, Wickramasinghe $\mathrm{S}$, Wickramasinghe R, Olupeliyawa A, Karunathilaka I. The students' voice: strengths and weaknesses of an undergraduate medical curriculum in a developing country, a qualitative study. BMC Research Notes. 2011;4(1):256.

22. Kogan JR, Shea JA. Course evaluation in medical education. Teaching and Teacher Education. 2007;23(3):251-64.

23. Moore AR. Medical humanities a new medical adventure. The New England Journal of Medicine. 1976;295(26):1479-80.

24. Arnott R, Bolton G, Evans M, Finlay I, Macnaughton J, Meakin R, et al. Proposal for an academic association for medical humanities. Medical Humanities. 2002;27:104-5.

25. Ousager J, Johannessen $\mathrm{H}$. Humanities in undergraduate medical education: a literature review. Academic Medicine. 2010;85(6):988-98.

26. Hafferty FW, Franks R. The hidden curriculum, ethics teaching, and the structure of medical education. Academic Medicine. 1994;69(11):861-71.

27. Cribb A, Bignold S. Towards the reflexive medical school: the hidden curriculum and medical education research. Studies in Higher Education. 1999;24(2):195.

28. Lempp H, Seale C. The hidden curriculum in undergraduate medical education: qualitative study of medical students' perceptions of teaching. British Medical Journal. 2004;329(7469):770-3.

29. Friedman L. The precarious position of the medical humanities in the medical school curriculum. Academic Medicine. 2002;77:320-2.

30. McCarthy PR, McCarthy HM. When case studies are not enough: integrating experiential learning into business curricula. Journal of Education for Business. 2006;81(4):201-4.

31. DasGupta S, Charon R. Personal illness narratives: using reflective writing to teach empathy. Academic Medicine. 2004;79(4):351-6.

32. Kripalani S, Bussey-Jones J, Katz M, Genao I. A prescription for cultural competence in medical education. Journal of General Internal Medicine. 2006;21(10):1116-20.

32. Shapiro J. Walking a mile in their patients' shoes: empathy and othering in medical students' education. Philosophy, Ethics, and Humanities in Medicine. 2008;3:10

34. Gaufberg E, Williams R. Reflection in a museum setting: the personal responses tour. Journal of Graduate Medical Education. 2011;3(4):546-9.

35. Mann K, Gordon J, MacLeod A. Reflection and reflective practice in health professions education: a systematic review. Advances in Health Sciences Education: Theory and Practice. 2009;14(4):595-621.

36. Morcke A, Dornan T, Eika B. Outcome (competency) based education: an exploration of its origins, theoretical basis, and empirical evidence. Advances in Health Sciences Education: Theory and Practice. 2012 Sep :1-13.

37. Parent F, Jouquan J, Ketele JM. CanMEDS and other "competency and outcome-based approaches" in medical education: clarifying the ongoing ambiguity. Advances in Health Sciences Education: Theory and Practice. 2013;18(1):115-22.

38. Cook D, West C. Perspective: reconsidering the focus on "outcomes research" in medical education: a cautionary note. Academic Medicine. 2013;88(2):162-7.

39. Evans M. Reflections on the humanities in medical education. Medical Education. 2002;36(6):508-13.

40. Fowell SL, Bligh JG. Recent developments in assessing medical students. Postgraduate Medical Journal. 1998;74(867):18-24.

41. Carlsen B, Glenton C. What about N? A methodological study of sample-size reporting in focus group studies. BMC Medical Research Methodology. 2011;11(1):26.

42. Schiekirka S, Reinhardt D, Heim S, Fabry G, Pukrop T, Anders S, et al. Student perceptions of evaluation in undergraduate medical education: a qualitative study from one medical school. BMC Medical Education. 2012;12(1):45.

\section{Appendix}

Focus Group Questions

- In your opinion, what is the purpose of the humanities curricula in medical education?

- How well does the OMNIBUS curriculum address the purpose you just described?

- How effective was the OMNIBUS curriculum in helping you to be a good doctor?

- What are the three things you like best about the curriculum?

- What are the three things that would be most important to change or improve in the curriculum?

- In the curriculum, the faculty teaches by leading discussions, lecturing, moderating debates, etc. Please describe the qualities and teaching strategies of the best teachers.

- What are the most appropriate methods for assessing students in a humanities curriculum? 